\title{
Where Are the Women in Orthopaedic Surgery?
}

\author{
Rachel S. Rohde MD, Jennifer Moriatis Wolf MD, Julie E. Adams MD
}

Published online: 18 April 2016

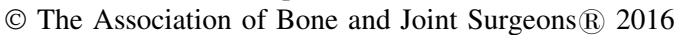

\begin{abstract}
Background Although women account for approximately half of the medical students in the United States, they represent only $13 \%$ of orthopaedic surgery residents and $4 \%$ of members of the American Academy of Orthopaedic Surgeons (AAOS). Furthermore, a smaller relative percentage of women pursue careers in orthopaedic surgery than in any other subspecialty. Formal investigations regarding the gender discrepancy in choice of orthopaedic surgery are lacking.

Questions/purposes (1) What reasons do women orthopaedic surgeons cite for why they chose this specialty? (2) What perceptions do women orthopaedic surgeons think might deter other women from pursuing this field? (3) What role does early exposure to orthopaedics and
\end{abstract}

Each author certifies that she, or a member of her immediate family, has no funding or commercial associations (eg, consultancies, stock ownership, equity interest, patent/licensing arrangements, etc) that might pose a conflict of interest in connection with the submitted article.

All ICMJE Conflict of Interest Forms for authors and Clinical Orthopaedics and Related Research ${ }^{\mathbb{R}}$ editors and board members are on file with the publication and can be viewed on request.

This work was performed at Ruth Jackson Orthopaedic Society, Rosemont, IL, USA.

R. S. Rohde $(\bowtie)$

Oakland University William Beaumont School of Medicine,

Michigan Orthopaedic Institute, PC, 26025 Lahser Road,

Southfield, MI 48033, USA

e-mail: rohders@gmail.com

J. M. Wolf

University of Connecticut, Farmington, CT, USA

J. E. Adams

Mayo Clinic, Austin, MN, USA mentorship play in this choice? (4) What professional and personal choices do women in orthopaedics make, and how might this inform students who are choosing a career path? Methods A 21-question survey was emailed to all active, candidate, and resident members of the Ruth Jackson Orthopaedic Society (RJOS, $n=556$ ). RJOS is the oldest surgical women's organization incorporated in the United States. An independent orthopaedic specialty society, RJOS supports leadership training, mentorship, grant opportunities, and advocacy for its members and promotes sex-related musculoskeletal research. Although not all women in orthopaedic practice or training belong to RJOS, it is estimated that $42 \%$ of women AAOS fellows are RJOS members. Questions were formulated to determine demographics, practice patterns, and lifestyle choices of women who chose orthopaedic surgery as a specialty. Specifically, we evaluated the respondents' decisions about their careers and their opinions of why more women do not choose this field. For the purpose of this analysis, the influences and dissuaders were divided into three major categories: personal attributes, experience/exposure, and work/life considerations.

Results The most common reasons cited for having chosen orthopaedic surgery were enjoyment of manual tasks (165 of 232 [71\%]), professional satisfaction (125 of 232 [54\%]), and intellectual stimulation (123 of 232 [53\%]). The most common reasons indicated for why women might not choose orthopaedics included perceived inability to have a good work/life balance (182 of 232 [78\%]), perception that too much physical strength is required (171 of 232 [74\%]), and lack of strong mentorship in medical school or earlier (161 of 232 [69\%]). Respondents frequently (29 of 45 [64\%]) commented that their role models, mentors, and early exposure to musculoskeletal medicine were influential, but far fewer (62 of 
231 [27\%]) acknowledged these in their top five influences than they did the more "internal" motivators.

Conclusions To our knowledge, this is the largest study of women orthopaedic surgeons regarding factors influencing their professional and personal choices. Our data suggest that the relatively few women currently practicing orthopaedics were attracted to the field because of their individual personal affinity for its nature despite the lack of role models and exposure. The latter factors may impact the continued paucity of women pursuing this field. Programs designed to improve mentorship and increase early exposure to orthopaedics and orthopaedic surgeons may increase personal interest in the field and will be important to attract a diverse group of trainees to our specialty in the future.

\section{Introduction}

Although women account for approximately half of the medical students in the United States, they represent only $13 \%$ of orthopaedic surgery residents and $4 \%$ of fellows of the American Academy of Orthopaedic Surgeons [22]. Furthermore, a smaller relative percentage of women pursue careers in orthopaedic surgery than in any other subspecialty [3], and orthopaedic surgery has the lowest representation of women residents and faculty [4].

The goals of this study were to determine the reasons why women in orthopaedic surgery selected the specialty and what perceived deterrents might explain why more women do not choose this field. Previous studies have suggested that a bias against surgical specialties overall may play a role in women's interest in orthopaedics [4]. Additionally, orthopaedic surgical programs with a stated commitment to diversity have shown higher percentages of women and underrepresented minorities [15, 21]. Finally, lack of mentorship and women faculty in training programs have been cited as potential causes of smaller numbers of women medical students pursuing this specialty [22]. We wanted to survey women both in residency and in active practice in orthopaedic surgery to elucidate specifically reasons for their choice of the specialty as well as their perceptions of why more women do not choose orthopaedics. This survey was designed to address the gap in knowledge regarding motivations, choices, and practice patterns of women orthopaedic surgeons. The results can educate and guide program directors, medical school curricula directors, and faculty in designing programs and strategies to increase personal interest of women in orthopaedic surgery.

We therefore asked: (1) What reasons do women orthopaedic surgeons cite for why they chose this specialty? (2) What perceptions do women orthopaedic surgeons think might deter other women from pursuing this field? (3) What role does early exposure to orthopaedics and mentorship play in this choice? (4) What professional and personal choices do women in orthopaedics make, and how might this inform students who are choosing a career path?

\section{Materials and Methods}

A 21-question survey was emailed to all active, candidate, and resident members of the Ruth Jackson Orthopaedic Society $(n=556)$. The survey was designed prospectively by committee and pilot-tested before distribution. Specifically, the survey was reviewed and completed by the seven members of the governing board with suggestions and critiques provided. The final survey then was generated and reviewed once more for accuracy and for online applications before being sent as an embedded link via email.

All participants were women members of the Ruth Jackson Orthopaedic Society (RJOS), an independent orthopaedic specialty society founded in 1983 as a mentoring network for women orthopaedic surgeons, which now supports leadership education, scientific grants, and advocacy. RJOS is open to both women and men, but primarily represents women medical students, residents, and practicing surgeons involved in or interested in orthopaedic surgery. Although not all women in orthopaedic practice or training belong to RJOS, it is estimated that $42 \%$ of women American Association of Orthopaedic Surgeons (AAOS) fellows are members of RJOS.

Questions were formulated to determine demographics, practice patterns, and lifestyle choices of women who chose orthopaedic surgery as a specialty. Specifically, we evaluated the respondents' decisions about their careers and their opinions of why more women do not choose this field. Participants were asked to rank the top five reasons for each influence and potential dissuader (Table 1). For the purpose of this analysis, the influences and dissuaders were divided subsequently into three major categories: personal attributes, experience/exposure, and work/life considerations (Table 1).

Survey data were analyzed by the authors.

\section{Statistical Analysis}

The study was open to all members of RJOS $(n=556)$. Responses were received from 232 of 556 members $(42 \%)$, all of whom were women. Most responders were practicing or retired members $(81 \%, \mathrm{n}=188)$, and $19 \%$, ( $n=44)$ were current trainees. Almost half of the respondents were from the Midwest or Northeast region 
Table 1. Positive influences and potential dissuaders of women considering orthopaedic surgery as a career

\begin{tabular}{lll}
\hline Category & Positive influences & Potential dissuaders \\
\hline Personal attributes & -Intellectually stimulating & -Perception that too much strength is required \\
& -Personally satisfying & -Dislike of working with hands/building things \\
& -Enjoy working with my hands/building things & -Dislike the operating room \\
& -Age and pathology range & -Too competitive/concerned about matching \\
& -Musculoskeletal conditions: operative and not & \\
Experience/exposure & -Exposure to MSK medicine in medical school & -Lack of exposure to MSK medicine in medical school \\
& -Strong mentors before or during medical school & -Lack of strong mentors before or during medical school \\
& -Family member is an orthopaedic surgeon & -Negative personal experience with orthopaedic surgeon \\
& -Personal history/interest in sports & -Negative personal experience with orthopaedic surgery \\
& -Self or family member had orthopaedic surgery & -No sports history or interest \\
Work/life considerations & -Ability to maintain work/life balance & -Fear of inability to maintain work/life balance \\
& -Autonomy & -Lack of autonomy \\
& -Compensation/financial security & -Lack of financial security
\end{tabular}

MSK $=$ musculoskeletal.

Fig. 1 The distribution of female orthopaedic surgeons ( + trainees) is noted geographically $(\mathrm{n}=232)$.

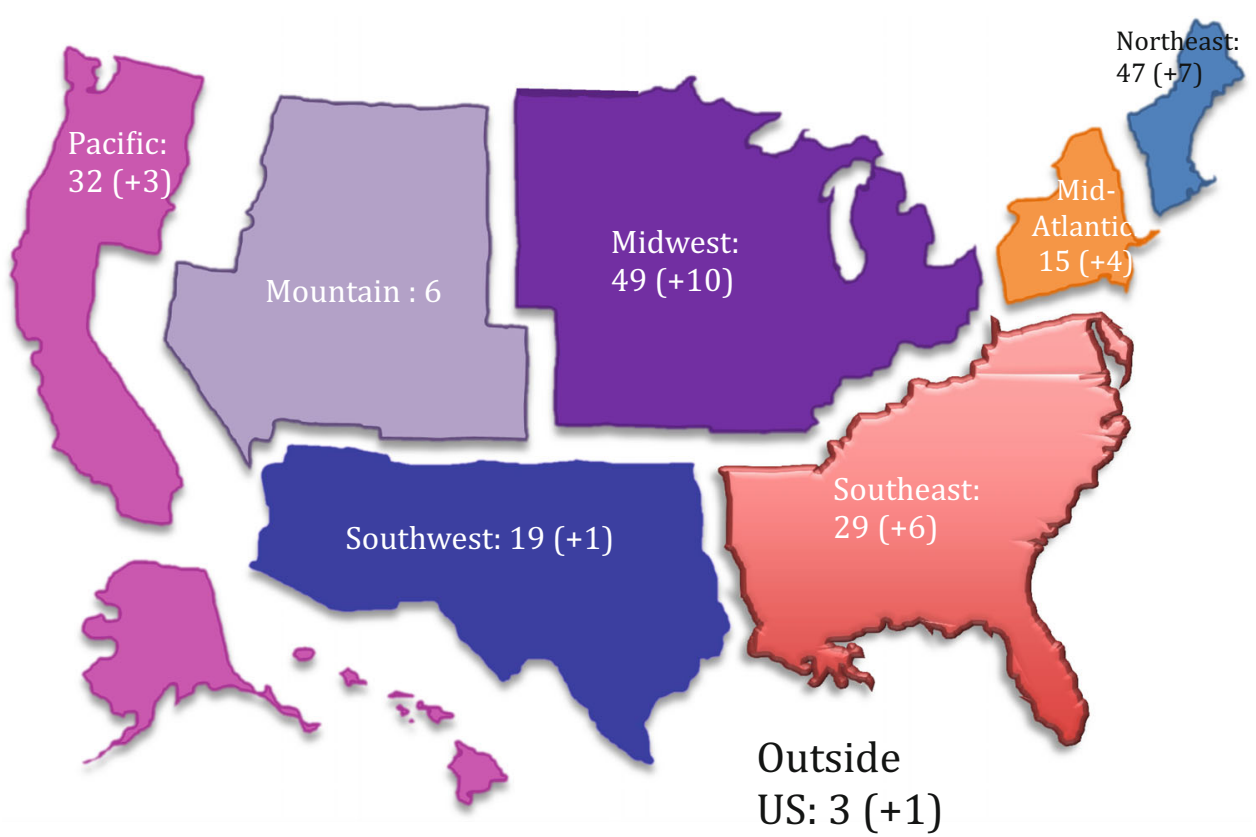

(Fig. 1). The most common specialties among respondents were hand $(24 \%)$, general orthopaedics $(20 \%)$, pediatric orthopaedics (19\%), and sports (15\%) (Fig. 2). Most reported practicing in an academic (42\%) or hospitalemployed (21\%) setting (Fig. 3). Two-thirds reported spending between 40 and 70 hours per week in direct patient care activities. Seventy-five percent of respondents considered themselves to be in a committed relationship, and $52 \%$ have children.
Men in the RJOS were excluded from this survey because this survey was focused on women self-reporting motivations to enter the field of orthopaedics.

\section{Results}

According to 232 respondents, the most common reasons cited for having chosen orthopaedic surgery were 
Fig. 2 The most common reported primary specialties of respondents included hand, general orthopaedics, pediatric orthopaedics, and sports $(\mathrm{n}=$ 209).
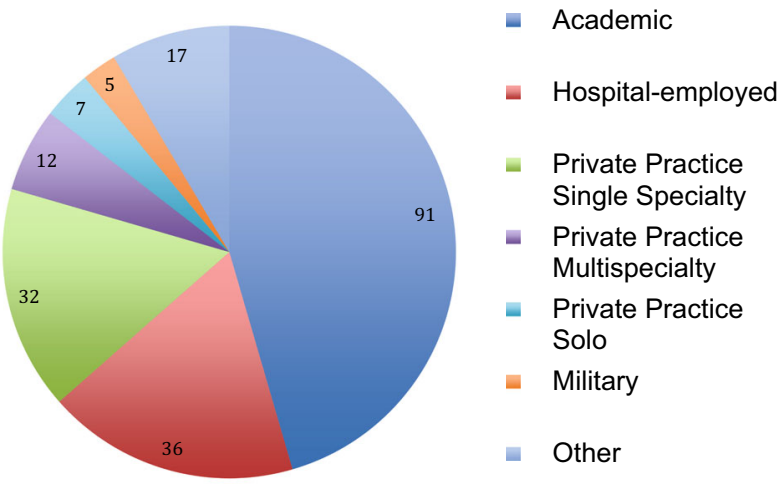

Fig. 3 The majority of female orthopaedic surgeons reported being in an academic or hospital-employed practice model $(n=200)$.

enjoyment of manual tasks (71\%), professional satisfaction $(54 \%)$, and intellectual stimulation (53\%). A majority of women orthopaedic surgeons were influenced primarily by personal attributes (Fig. 4). Relatively few reported that mentorship (27\%) or exposure to musculoskeletal medicine during or before medical school (16\%) inspired them.

The most common reasons proposed for why women might not choose orthopaedics included examples from all three categories: work/life considerations, personal attributes, and experience or mentorship. Seventy-eight percent of responders felt that orthopedic surgeons were perceived as unable to have a good work/life balance, whereas $74 \%$ felt that there was a perception that too much physical strength is required, and $70 \%$ of respondents felt there was a lack of strong mentorship in medical school or earlier (Fig. 5).

Early exposure to orthopaedics played a less influential role than personal interests, where only $43 \%$ of respondents reported an influence of strong mentors in medical school or earlier or positive role models who were orthopaedic

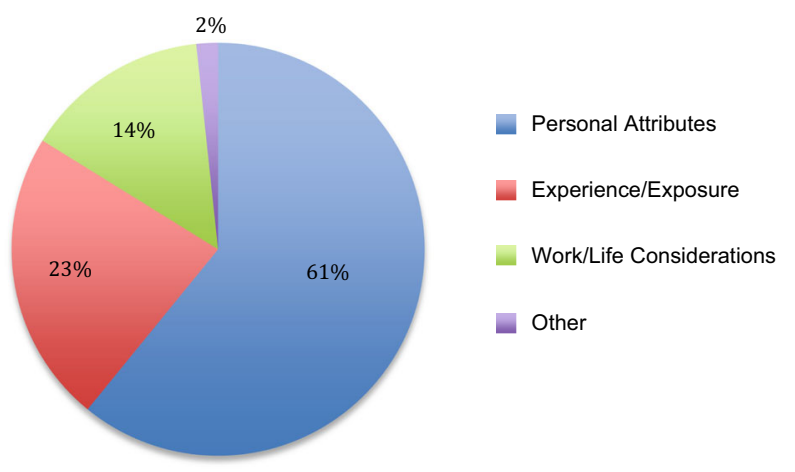

Fig. 4 The majority of positive influences on women who chose orthopaedic surgery $(61 \%[n=231$ of 232$])$ were categorized as "personal attributes".

surgeons (familial or not) in their top five influences. Exposure to musculoskeletal medicine in medical school was cited by only $16 \%$ as being one of the top five influences. Mentorship also played a lesser role than personal interests, where over $21 \%$ of respondents $(n=49$ of 232$)$ reported having only one woman resident in their training program. Most reported having one or no woman faculty member in orthopaedic clinical (52\%), orthopaedic research $(82 \%)$, and nonorthopaedic clinical $(70 \%)$ educational activities.

Our data suggest that women who choose orthopaedic surgery as a profession are most commonly either general orthopaedic surgeons $(20 \%)$ or choose a subspecialty in hand, pediatric orthopaedics, or sports. They more commonly are in academic or hospital-employed practices. These women are often in a committed relationship (75\%), and approximately half have one or more children $(52 \%)$. These data are helpful to students potentially interested in considering a career in orthopaedic surgery, suggesting the specialties and practice settings that current women orthopaedic surgeons are engaged in and also providing 


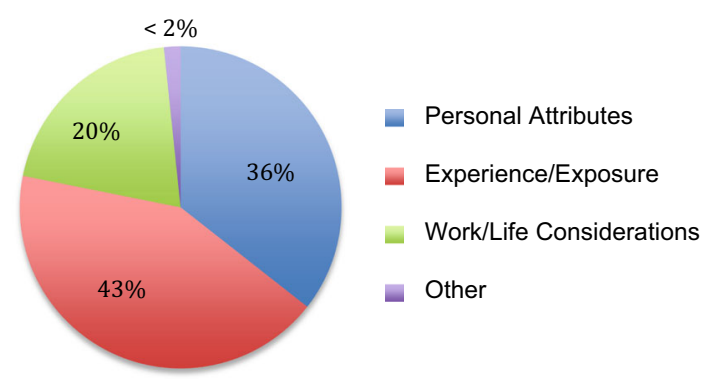

Fig. 5 Potential dissuaders for women considering orthopaedic surgery represented all categories $(n=231$ of 232).

limited information about the personal lives of women orthopaedic surgeons.

\section{Discussion}

The paucity of women in orthopaedic surgery persists despite increasing proportionate representation of women in medical school and in other traditionally male-dominated subspecialties such as neurosurgery and thoracic surgery $[3,11,20]$. This finding is likely multifactorial, involving both internal and external influences, both real and perceived. Our study was designed to seek the reasons why women orthopaedic surgeons chose their career and the perceived factors influencing that decision; we also wished to understand the reasons women orthopaedic surgeons believe that more women do not pursue this field. To our knowledge, this is the largest study of women orthopaedic surgeons regarding why they chose orthopaedics, why they think other women might not, and the lifestyle and practice choices they have made to allow them to fulfill professional and personal goals.

This study has several limitations. First, the survey was limited to members of the RJOS, and the experiences and opinions of the members might not reflect those of all women orthopaedic surgeons. However, this is the largest group of women orthopaedic surgeons of which we are aware, and this group has the advantages of internal diversity including subspecialty, geographic location, age, years out of training, and practice environment. Whether the RJOS membership is reflective of women orthopaedic surgeons in general is a difficult question to answer with accuracy. The most recent available numbers from the AAOS' "Orthopaedic Practice in the US 2014" census indicate that the AAOS membership is comprised of $92.1 \%$ male and $5.0 \%$ female orthopaedic surgeons; however, these percentages are gleaned from 26,914 members who responded to the 2014 census, and $2.9 \%$ of the respondents did not indicate a gender. That aside, 1337 respondents indicated that they were female. The membership of RJOS at the time of the survey was 556, which would suggest that $42 \%$ of female orthopaedic surgeons in AAOS are members of RJOS. Geographic location is the only category of data that is stratified by gender in the AAOS census. The highest percentages of women geographically in the RJOS respondents were from the Midwest (24\%), Northeast (23\%), and Southeast (14\%); the highest percentages of women respondents in the AAOS census were located in the Southeast (23\%), Midwest (21\%), and Pacific (21\%). The AAOS does not have data stratified by gender regarding the other demographic and practice parameters assessed by our survey available for comparison. Compared with the general AAOS population, the majority of RJOS members work in academic or hospital-employed positions, which contrasts to the practice patterns of AAOS members in general, only $31 \%$ of whom practice in those settings. Additionally, response bias within RJOS may have influenced this study's findings, because those RJOS members (58\% of membership) who did not participate in the survey might have different views and opinions from the cohort of respondents. Finally because all answers were obtained from women orthopaedic surgeons, the reasons why women might not choose orthopaedic surgery are drawn from perceptions of current orthopaedic surgeons, which may not be entirely valid. Johnson et al. [12] showed that medical students who chose not to go into orthopaedic surgery more frequently chose specialty based on medical school faculty and clerkships compared with orthopaedicsbound students who chose the specialty before medical school.

Interestingly in our study, the most common reasons cited for having chosen orthopaedic surgery were enjoyment of manual tasks, professional satisfaction, and intellectual stimulation. Personal attributes and preferences have been noted to play a role in women's ranking lists as well. Huntington et al. queried orthopaedic match applicants to a single orthopaedic program with a $28 \%$ response rate and noted that women (32 of 207 [15.5\%]) rated personal interactions and proximity to family and friends in ranking programs [9].

In Blakemore et al.'s evaluation of women in orthopaedic residency, the authors noted that the rate of female medical students entering orthopaedics has remained constant at $0.6 \%$ over time and postulated that perceptions of need for strength and negative impact on family choice were reasons for low numbers of women [3]. These are similar to our cohort's data indicating perceptions of a requirement for physical strength and inability to achieve work/life balance as two of the top three dissuaders.

The perception of difficulty achieving a work/life balance shown by our data is consistent with concerns shown in other studies [5] as are the differences between perception and reality. In one study, concern regarding the 
perceived inability to have a rewarding personal life and a surgical career was expressed by medical students but was not simultaneously corroborated by women practicing general surgery [16].

In addition, our study showed the unexpected finding that relatively few women stated that mentorship or exposure to musculoskeletal medicine during or before medical school prompted them to pursue a career in orthopaedic surgery. A minority of respondents ranked a strong role model in their top five reasons for having chosen orthopaedics in our study. However, many respondents who responded with free text to that question cited specific role models who had influenced their decisions. These data suggest that mentorship-when present-plays a role in career choice and advancement, similar to previous assertions in studies by Flint et al. and Pellegrini [7, 17].

More than half of women respondents noted that there was one or no woman faculty members in their residency program. The participation of women faculty members has been postulated to be a factor in the uneven distribution of woman orthopaedic residents in the United States [22]. Representation of women on faculty has been associated with whether women medical students choose surgery as a career [14]. These data are concordant with prior work that suggests an absence of a "critical mass" of women may dissuade female applicants from choosing a given field or residency program $[22,24]$. A study in Australia noted that $72 \%$ of female medical students cited a lack of woman role models as a reason for not pursuing a surgical career [6]. Role models have been shown to attract medical students to surgical subspecialty training $[8,19,25]$, and an interested mentor has been cited as the most important factor in a medical student initially being attracted to a field [10]. Our cohort not identifying a mentor as one of the top influences might reflect the lack of mentors for interested women rather than a lack of their importance.

Lack of early exposure to orthopaedics, which is accompanied by decreased access to potential role models, has been identified as an issue for both men and women medical students $[2,12]$. Bernstein et al. reported a positive correlation between required musculoskeletal education in medical school and higher rates of application for orthopaedic residency with a notable impact on women, who had a $75 \%$ higher rate of orthopaedic residency applications. These findings suggest that early exposure does make a difference in women's consideration of orthopaedics as a career [2]. Students who choose orthopaedic surgery are more likely than others to have reported experiences with influencers before medical school, and over half of respondents who chose orthopaedics had made that decision before clerkships [12].

Our results indicated that women respondents chose orthopaedic surgery because of intellectual stimulation and enjoyment of manual tasks, similar to the report of patient care issues being the primary reason for specialty choice in the survey study of both men and women by Johnson et al. [12]. The prolonged hours of surgical training appear less daunting when they are limited by work-hour regulations, and this might account for the increased pursuit of surgical residencies by women [1]. The fact that women choose orthopaedics for occupation-related and intellectual reasons correlates well with the finding in a study of 90 residents that women and men in residency performed similarly by objective and subjective measures [15]. Women reported higher satisfaction with career choice than their male colleagues [18]. Although increased attrition rates of women orthopaedic surgery residents have been described in the past [23], a recent study does not substantiate this finding [18]. Additionally, concerted efforts to increase diversity through targeted programming and recruitment have been described [21]. A positive trend in women and Hispanic trainees in orthopaedic surgery was attributed to the orthopaedic diversity awareness program [13].

In conclusion, our data suggest that the relatively small number of women currently practicing orthopaedics was attracted to the field because of their individual affinity for its nature despite the lack of role models and exposure. The latter factors likely play prominent roles in the continued paucity of women pursuing this field. Moreover, the perception that women who pursue orthopaedic surgery do so at the expense of a satisfying lifestyle is inaccurate. Programs designed to improve mentorship and increase early exposure to orthopaedics and orthopaedic surgeons will be important to attract a diverse group of medical students, representative of the general population, to orthopaedic residency going forward.

\section{References}

1. Anakwenze OA, Kancherla V, Baldwin K, Levine WN, Mehta S. Orthopaedic residency applications increase after implementation of 80-hour workweek. Clin Orthop Relat Res. 2013;471:17201724.

2. Bernstein J, Dicaprio MR, Mehta S. The relationship between required medical school instruction in musculoskeletal medicine and application rates to orthopaedic surgery residency programs. J Bone Joint Surg Am. 2004;86:2335-2338.

3. Blakemore LC, Hall JM, Biermann JS. Women in surgical residency training programs. J Bone Joint Surg Am. 2003;85:24772480.

4. Day CS, Lage DE, Ahn CS. Diversity based on race, ethnicity, and sex between academic orthopaedic surgery and other specialties: a comparative study. J Bone Joint Surg Am. 2010; 92:2328-2335.

5. Dorsey ER, Jarjoura D, Rutecki GW. The influence of controllable lifestyle and sex on the specialty choices of graduating US medical students, 1996-2003. Acad Med. 2005;80:791-796. 
6. Ek EW, Ek ET, Mackay SD. Undergraduate experience of surgical teaching and its influence and its influence on career choice. ANZ J Surg. 2005;75:713-718.

7. Flint JH, Jahangir AA, Browner BD, Mehta S. The value of mentorship in orthopaedic surgery resident education: the residents' perspective. J Bone Joint Surg Am. 2009;91:1017-1022.

8. Harris LM, Chaikof EL, Eidt JF. Altering the career choice: can we attract more women to vascular surgery? J Vasc Surg. 2007;45:846-848.

9. Huntington WP, Haines N, Patt JC. What factors influence applicants' rankings of orthopaedic surgery residency programs in the National Resident Matching Program? Clin Orthop Relat Res. 2014;472:2859-2866.

10. Illig KA, Kalata E, Reed A, Glass C, Gillespie DL. Recruiting strategies for potential $0+5$ vascular residency applicants. Ann Vasc Surg. 2012;26:1-9.

11. Jagsi R, Griffith KA, DeCastro RA, Ubel P. Sex, role models, and specialty choices among graduates of US medical schools in 2006-2008. J Am Coll Surg. 2014;218:345-352.

12. Johnson AL, Sharma J, Chinchilli VM, Emery SE, McCollister Evarts C, Floyd MW, Kaeding CC, Lavelle WF, Marsh JL, Pellegrini VD Jr, Van Heest AE, Black KP. Why do medical students choose orthopaedics as a career? J Bone Joint Surg Am. 2012;94:e78.

13. Kane K, Rosero EB, Clagett GP, Adams-Huet B, Timaran CH. Trends in workforce diversity in vascular surgery programs in the United States. J Vasc Surg. 2009;49:1514-1519.

14. Neumayer L, Kaiser S, Anderson K, Barney L, Curet M, Jacobs D, Lynch T, Gazak C. Perceptions of women medical students and their influence on career choice. Am J Surg. 2002;183:146-150.

15. Okike K, Utuk ME, White AA. Racial and ethnic diversity in orthopaedic surgery residency programs. J Bone Joint Surg Am. 2011;93:e107.
16. Park J, Minor S, Taylor RA, Vikis E, Poenaru D. Why are women deterred from general surgery training? Am J Surg. 2005; 190:141-146.

17. Pellegrini VD Jr. Mentoring during residency education: a unique challenge for the surgeon? Clin Orthop Relat Res. 2006;449:143148.

18. Pico K, Gioe TJ, Vanheest A, Tatman PJ. Do men outperform women during orthopaedic residency training? Clin Orthop Relat Res. 2010;468:1804-1808.

19. Quillin RC 3rd, Pritts TA, Davis BR, Hanseman D, Collins JM, Athota KP, Edwards MJ, Tevar AD. Surgeons underestimate their influence on medical students entering surgery. J Surg Res. 2012;177:201-206.

20. Renfrow JJ, Rodriguez A, Liu A, Pilitsis JG, Samadani U, Ganju A, Germano IM, Benzil DL, Wolfe SQ. Positive trends in neurosurgery enrollment and attrition: analysis of the 2000-2009 female neurosurgery resident cohort. J Neurosurg. 2015:1-6.

21. Thomas CL. African Americans and women in orthopaedic residency. The Johns Hopkins experience. Clin Orthop Relat Res. 1999;362:65-71.

22. Van Heest AE, Agel J. The uneven distribution of women in orthopaedic surgery resident training programs in the United States. J Bone Joint Surg Am. 2012;94:e9.

23. Walker JL, Janssen H, Hubbard D. Gender differences in attrition from orthopaedic surgery residency. J Am Womens Assoc. 1993;48:182-184, 193.

24. WINS White Paper Committee, Benzil DL, Abosch A, Germano I, Gilmer H, Maraire JN, Muraszko K, Pannullo S, Rosseau G, Schwartz L, Todor R, Ullman J, Zusman E. The future of neurosurgery: a white paper on the recruitment and retention of women in neurosurgery. $J$ Neurosurg. 2008;109:378-386.

25. Wright S, Wong A, Newill C. The impact of role models on medical students. J Gen Intern Med. 1997;12:53-56. 